\title{
Stress-Strain Relationships in Yarns Subjected to Rapid Impact Loading: 4. Transverse Impact Tests*
}

\author{
Jack C. Smith, Frank L. McCrackin, Herbert F. Schiefer, Walter K. Stone, \\ and Kathryn M. Towne
}

\begin{abstract}
If a textile yarn segment clamped at each end, is impacted transversely at the midpoint, the stress-strain curve for this yarn can be obtained from measurements on a high speed photographic record of the motion of the yarn. This paper describes the apparatus and procedure used. Stress-strain curves for high rates of straining, of the order of 5,000 percent per second, obtained by this method are given for high-tenacity nylon, Fortisan, and Fiberglas. Comparison with stress-strain data obtained at conventional rates shows that these materials have higher initial moduli, and that their stress-strain curves remain linear up to higher stress values when the testing rate is high. The breaking tenacities are slightly greater and breaking elongation slightly smaller at these high test rates.
\end{abstract}

\section{Introduction}

In previous papers of this series $[1,2,3]^{1}$ the behavior of textile yarns subjected to longitudinal impacts of order of magnitude $50 \mathrm{~m} / \mathrm{sec}$ was discussed. Equipment using high speed photography was described. A procedure for obtaining stressstrain curves at initial rates of straining of the order of 5,000 percent per second $(300,000 \%$ per min) was given. The concept of a limiting breaking velocity, approximating the lowest velocity at which a textile yarn will rupture immediately upon tensile impact, was introduced, and values of this characteristic quantity were given for several different yarns.

Equipment for studying the behavior of yarns impacted transversely at velocities of order of magnitude $50 \mathrm{~m} / \mathrm{sec}$ has now been constructed. This equipment is described here. A method of obtaining stress-strain curves from photographs of the successive configurations of a clamped yarn subjected to transverse impact is outlined. Stress-strain data obtained in this way are given for high-tenacity yarns of nylon, Fortisan, ${ }^{2}$ and Fiberglas. ${ }^{3}$

\section{Apparatus}

An assembly of the transverse impact equipment is shown in figure 1 . The yarn specimen is clamped to a rigid massive table, $\hat{A}$, on which a coordinate grid system is inscribed. Central transverse impact is made by a freely flying projectile that has been struck by a rapidly rotating hammer, H. Apparatus for rotating and stopping the hammer is separate from the specimen table in order to avoid jarring.

The 6 -in. hammer rotates under a powerful torque through an arc of $270^{\circ}$ before striking. The force to rotate the hammer is applied at the surface of a 2 -in. shaft by straps from four springs, which can be extended up to $20 \mathrm{in}$. by a motor. At full extension the total tension in the four springs is $800 \mathrm{lb}$. The hammer is held in place by a latch, which can be

${ }^{*}$ This paper is being republished by the Textile Research Journal, volume 26 November 1956 .

1 Figures in brackets indicate the literature references at the end of this paper. 23 Proprietary names for deacetylated cellulose acetate and fiber glass, respectively. suddenly released by a solenoid. Projectile speeds have been measured as high as $70 \mathrm{~m} / \mathrm{sec}$.

Reflected images of the specimen after impact are photographed by the high-speed camera, C, on the table. Either 7,000 or 14,000 pictures per second can be taken depending on which of two Fastex cameras is used for this purpose.

Other parts of the equipment shown in figure 1 are the control unit, $\mathrm{CU}$, which puts timing pips on the film and triggers the hammer when the camera is up to speed, the five $750 \mathrm{~W}$ flood lamps, L, for illuminating the specimen, the mirror, M, for reflecting the image of the specimen into the camera, and the box, $\mathrm{B}$, for catching the projectile.

Figure 2 shows a closeup of the specimen, specimen table, projectile, hammer, and driving springs. The shapes that the specimen assumes after impact, as recorded by the camera, are shown in figure 3 for a typical yarn specimen.

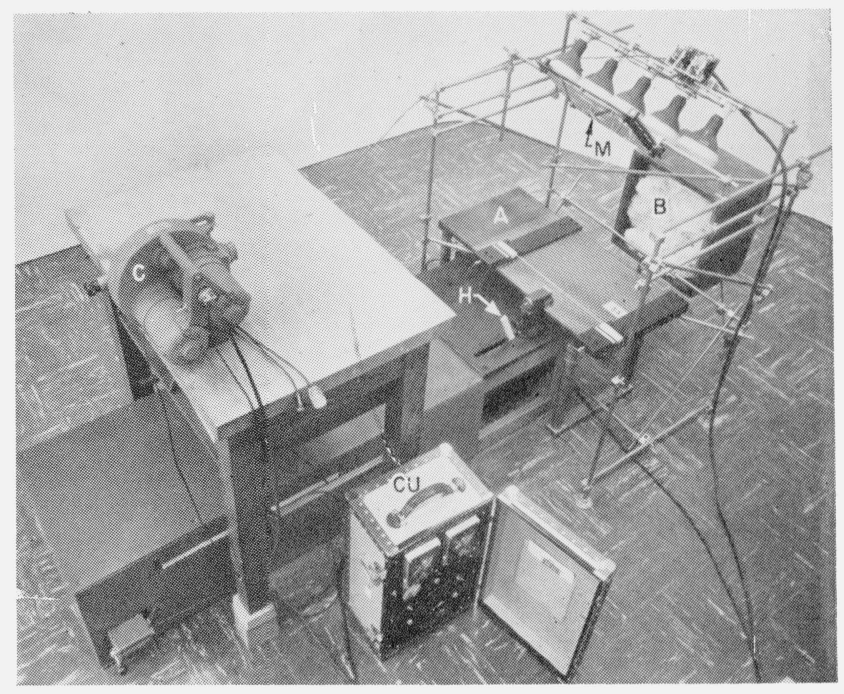

FIGURE 1. Apparatus for impacting yarn specimens transversely.

A, Table; H, hammer; C, camera; CU, control unit: $\mathrm{L}_{4}$, lamgs; $\mathbf{M}$, mirror; B catch box. 


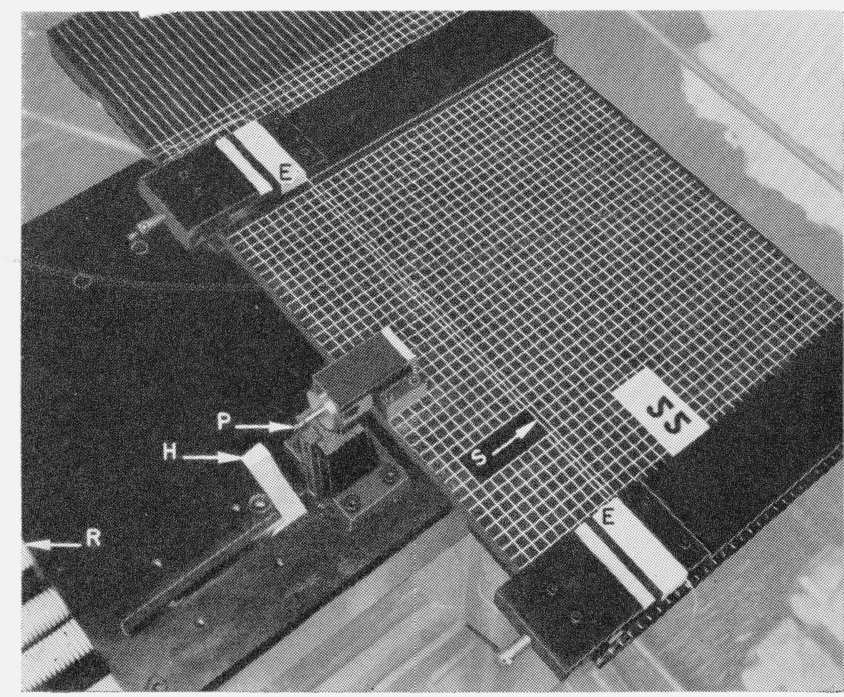

FIGURE 2. Detail of yarn impacting apparatus.

S, Yarn specimen; E, E, specimen clamps; $\mathrm{P}$, projectile; $\mathrm{H}$, hammer; R, springs.

\section{Analysis of the Data}

When a yarn is struck transversely by a projectile traveling at a velocity $V$, a longitudinal strain wave $^{4}$ is propagated along the yarn with velocity $C$ outwards in each direction from the point of impact (see curve a in fig. 4). In the strained region between these wave fronts, the material of the yarn is set in motion toward the point of impact. This inward flowing material forms itself into a tent-shaped wave with the impacting projectile at the vertex. The material forming the tent moves in the direction of the projectile with the velocity of the projectile. The base of the tent propagates outward as a transverse wave with velocity $U$.

The velocity, $U$, is a function of the tension, $T$, and strain, $\epsilon$, in the yarn in the region of the transverse wave front, and of the mass per unit length, $M$ of the unstrained yarn. This relationship, derived separately, is given by

$$
U=\sqrt{\frac{T}{M(1+\epsilon)}},
$$

${ }^{4}$ For high-tenacity nylon the magnitude of the longitudinal strain is about 0.3 percent for a transverse impact velocity of $50 \mathrm{~m} / \mathrm{sec}$ and 0.6 percent for 75 $\mathrm{m} / \mathrm{sec}$.

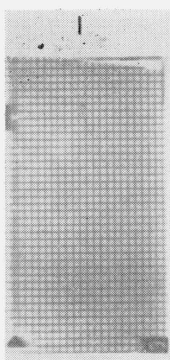

8

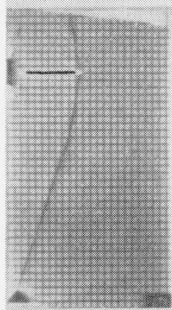

15

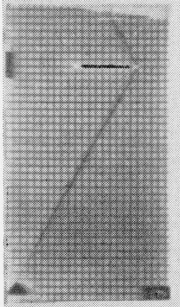

2

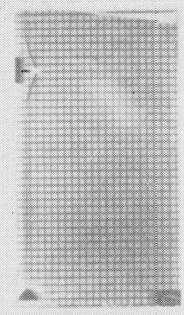

9

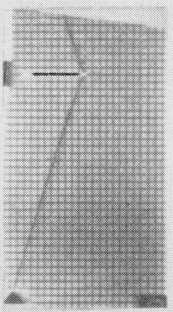

16

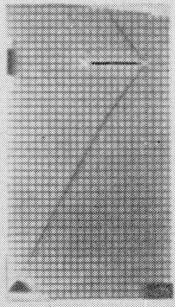

3

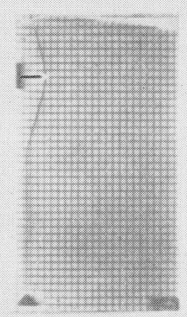

10

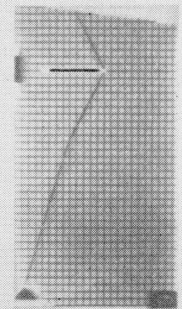

17

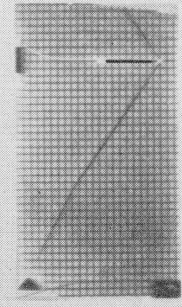

4

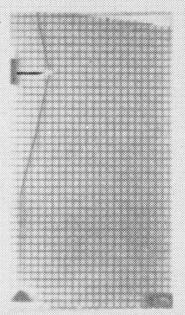

II

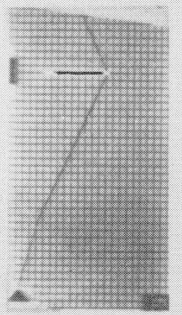

18

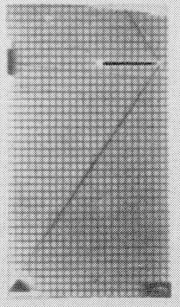

5

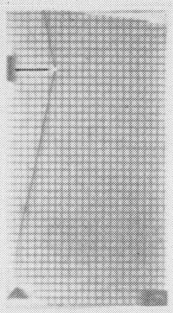

12

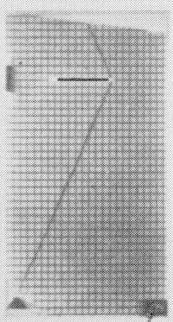

19

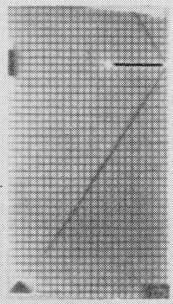

6

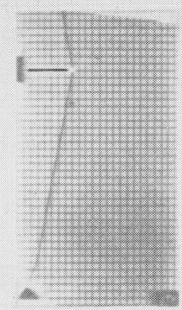

13

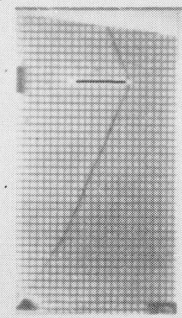

20

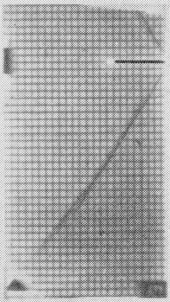

7

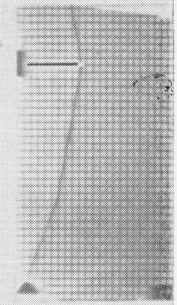

14

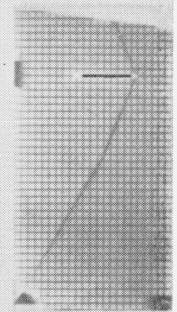

21

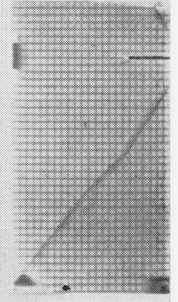

FIGURE 3. Film strips showing motion of projectile and configurations of yarn specimen during a transverse impact test.

Impact occurred between frames 1 and 2, upper left. Strand by strand breakage began at frame 19, lower right. Camera speed was 6984 frames per second, but every other frame only was printed in this illustration. 


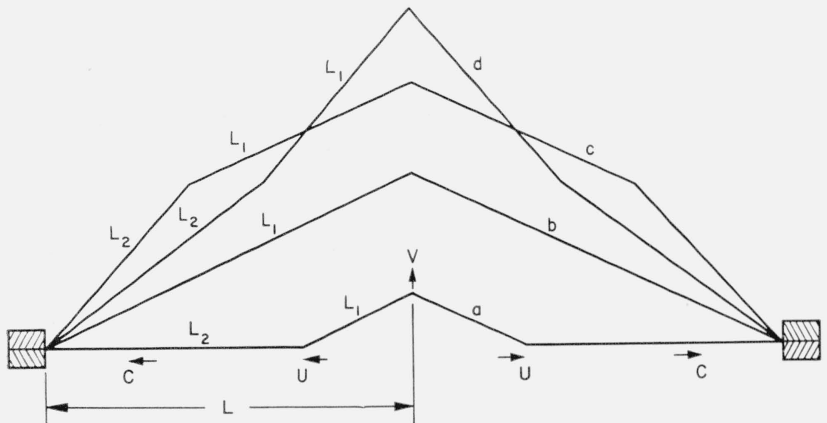

FIGURE 4. Typical configuration of yarn specimen after transverse impact.

Curve a, Transverse wave propagating outwards toward clamps; $b$, transverse wave a clamps; c, reflected transverse wave propagating Wave at instant of reflection at clamps; c, reflected transverse wave propagating after reflection at projectile.

where $U$ is in Lagrangian coordinates. ${ }^{5}$ The transverse wave always propagates more slowly than the longitudinal strain wave.

When the yarn specimen is clamped at two points equidistant from the point of impact, reflections of the longitudinal strain wave will alternately occur at the clamps and at the projectile. At these reflections the local strain increases by small increments. After several of these reflections have occurred and before the rupture strain is attained, the transverse wave front usually arrives at the clamp. As the material forming the tent moves in the direction of the projectile and with the velocity of the projectile, it is apparent that the arrival of the transverse wave at the stationary clamp is equivalent to a new impact giving rise to a new longitudinal strain wave as well as a new transverse wave.

It is appropriate to consider this behavior as a reflection of the transverse wave at the clamp. This reflection is manifested by a marked change in the configuration of the specimen, a sudden increase in local strain, and a sudden increase in transverse wave velocity. A similar reflection occurs when the transverse wave arrives at the projectile. Again a marked change occurs in the configuration of the specimen, together with a sudden increase in local strain and a sudden increase in transverse wave velocity. These effects are readily discernible in the series of pictures taken with the high-speed camera, figure 3 , and in the typical successive configurations $\mathrm{a}, \mathrm{b}, \mathrm{c}$, and $\mathrm{d}$ in figure 4 . In addition to the phenomena just described, interactions will also take

${ }^{5}$ A Lagrangian system of coordinates is fixed to the specimen, moving and extending with it. For example, in this work the lengths $L_{1}$ and $L_{2}$ in figure 4 are transformed to the Lagrangian coordinate lengths $\mathcal{L}_{1}$ and $\mathcal{L}_{2}$ by the expres sions

and

$$
\mathcal{L}_{1}=\frac{L_{1} L}{L_{1}+L_{2}}
$$

$$
\mathcal{L}_{2}=\frac{L_{2} L}{L_{1}+L_{2}},
$$

where $L$ is the distance from the impact point to the clamp in the unstrained specimen. Velocity $U$ is given by

$$
U=\frac{d \mathcal{L}_{1}}{d t}=\frac{-\mathcal{L}_{2}}{d t}
$$

place between the longitudinal and the transverse waves. This complex behavior will be described in future papers in this series. It has also been considered theoretically by Craggs [4].

The photographic data, such as that shown in figure 3, are analyzed as follows: The positions of the transverse wave front, the projectile, and clamp for one side of the yarn specimen are measured from enlargements obtained with a microfilm reader, and configurations of the specimen are drawn on graph paper. The lengths $L, L_{1}$, and $L_{2}$, as defined in figure 4 , are then measured for the configuration corresponding to each frame of the photographic record, and the average strain, $\bar{\epsilon}$, in the specimen is computed from the formula

$$
\bar{\epsilon}=\frac{L_{1}+L_{2}-L}{L} .
$$

From these length measurements the positions of the transverse wave front, given by $\mathcal{L}_{2}$ in Lagrangian coordinates are calculated for each frame. The differences between values of $\mathcal{L}_{1}$ for successive frames are plotted at each midpoint between these frames, and from the curve obtained the value corresponding to each frame is read off. Velocity $U$ is equal to the product of this quantity by the camera speed in frames per second. The tension in the specimen is then found from the formula ${ }^{6}$

$$
T=U^{2} M(1+\bar{\epsilon}) .
$$

If $T$ is expressed in terms of the more familiar textile unit of grams per denier, and $U$ is in centimeters per second, the equation for tension is

$$
T=1.134 \times 10^{-9} U^{2}(1+\bar{\epsilon}) .
$$

Typical data from a test with a nylon specimen are shown plotted in figures 5 and 6 . Curve $\mathrm{A}$ of figure 5 is a plot of average strain, $\bar{\epsilon}$, versus frame number. The curve is scalloped with abrupt changes in strain occurring at each reflection of the transverse wave (designated by $\mathrm{R}$ ). The rate of straining increases as the strain increases, causing the stress-strain curve obtained to have a steeper slope at rupture strain than it would have had if the sample had been elongated uniformly at the initial rate.

Elongation at break is estimated from several considerations. Frequently the specimen is seen to break. Often the transverse wave velocity decreases abruptly or the configuration of the specimen becomes irregular, indicating a decrease in tension. Breaking frequently occurs upon reflection of the transverse wave. The time of break can usually be localized to within one frame.

Curve B of figure 5 is a plot of transverse wave velocity in centimeters per frame versus frame number. This curve is also scalloped, velocity increasing as the tension increases. The character

${ }^{6}$ In using this equation, the local strain at the transverse wave front should be used instead of the average strain, $\bar{\epsilon}$. This local strain differs at most from the average strain by the magnitudes of the local strain pulses traversing the specimen. At the projectile velocities used in the tests of this paper these strain pulses are small and the approximation made is warranted. 


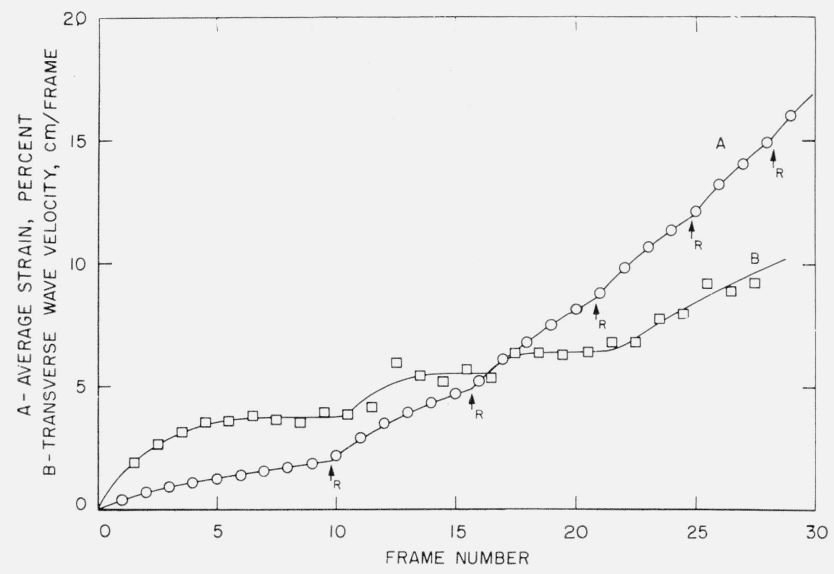

Figure 5. Average strain and transverse wave velocity as function of time (photographic frame number) for a transversely impacted nylon yarn specimen.

Curve A, Average strain versus frame number; B, transverse wave velocity versus frame number. Points $R$ indicate frames in which a reflection of the transverse wave occurred.

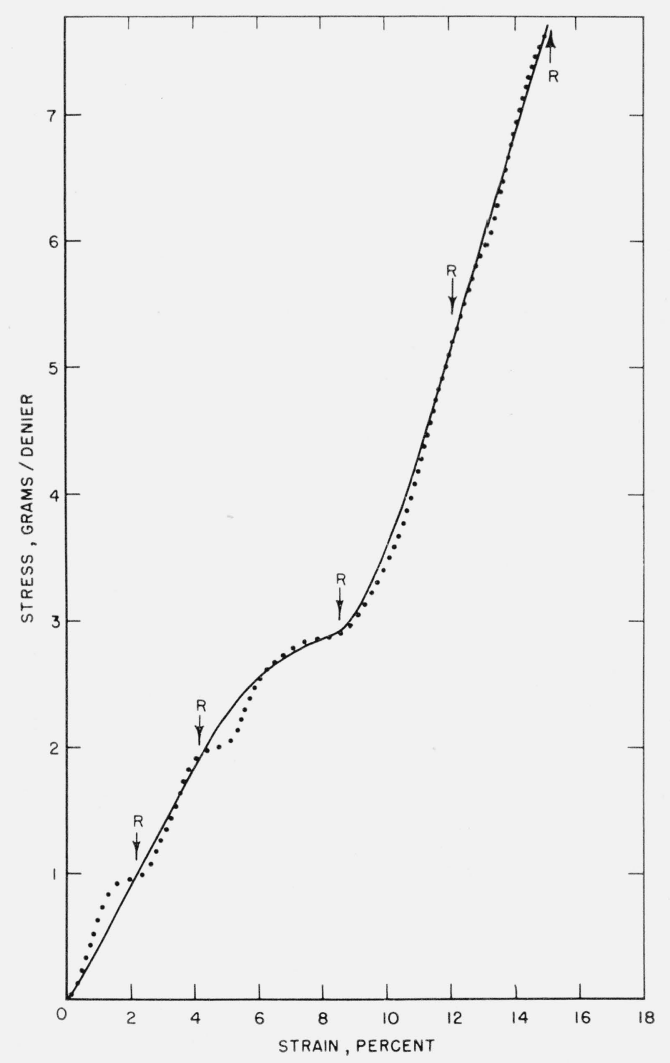

FIGURE 6. Stress-strain curve for a transversely impacted nylon yarn specimen.

Broken line, scalloped curve obtained from data shown in figure 5; solid line, smoothed-out stress-strain curve.

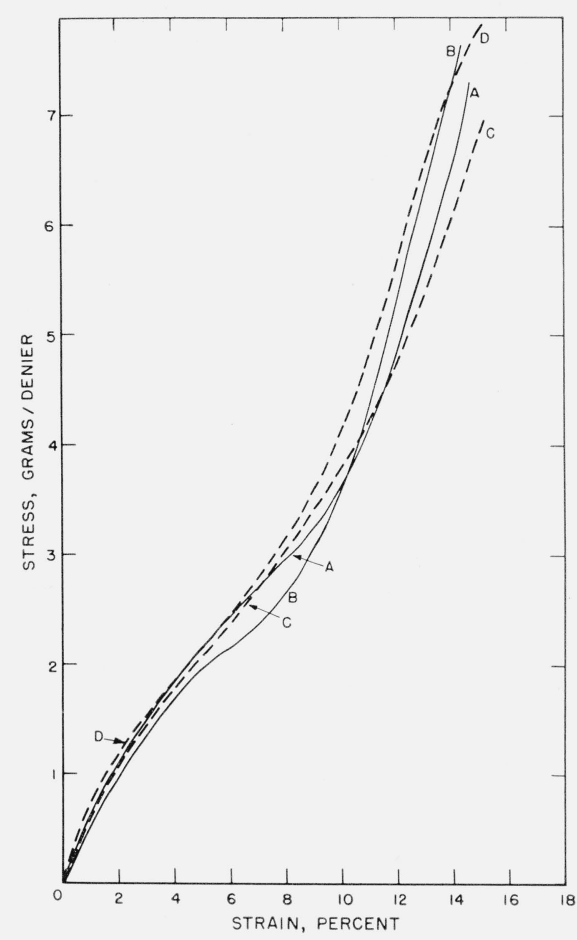

FIGURE 7. Stress-strain curves for high-tenacity nylon specimons impacted transversely.

A, Impact speed $45 \mathrm{~m} / \mathrm{sec}$, half-length $30 \mathrm{~cm}$, rate of straining 4,000 percent per second; B, impact speed $45 \mathrm{~m} / \mathrm{sec}$, half-length $20 \mathrm{~cm}$, rate of straining 5,500 percent per second; C, impact speed $65 \mathrm{~m} / \mathrm{sec}$, half-length $30 \mathrm{~cm}$, rate of straining straining 8,500 percent per second.

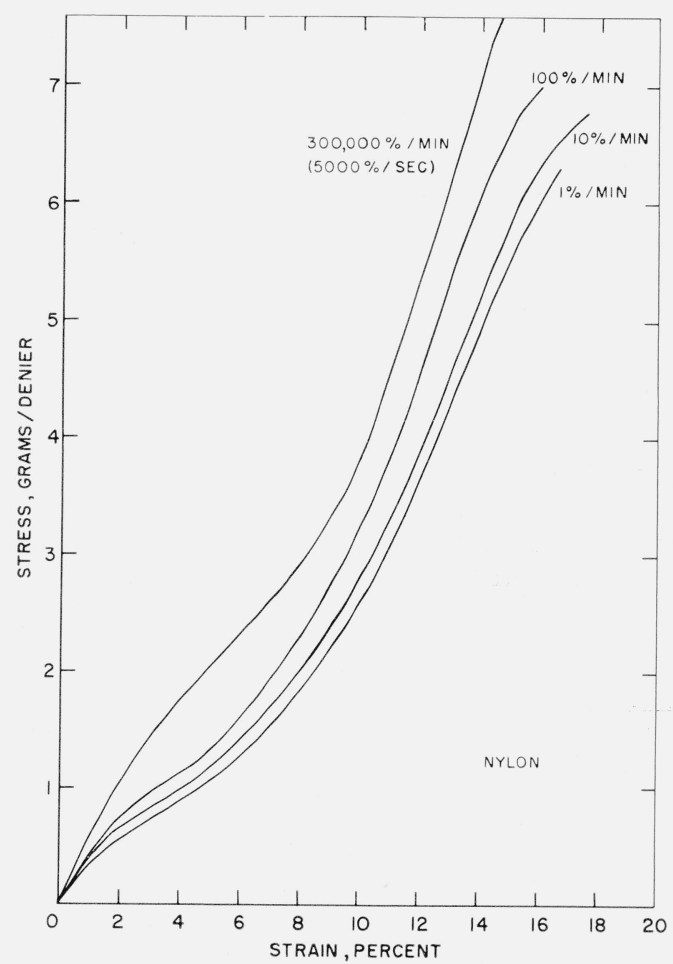

FIGURE 8. Stress-strain curves for high-tenacity nylon at various rates of straining.

86 
TABLE 1. Transverse impact data for high-tenacity nylon a

\begin{tabular}{|c|c|c|c|c|c|c|c|}
\hline Test & $\begin{array}{l}\text { Impact } \\
\text { velocity }\end{array}$ & $\begin{array}{l}\text { Specimen } \\
\text { length }\end{array}$ & Rate of straining & $\begin{array}{l}\text { Time to } \\
\text { break }\end{array}$ & $\begin{array}{l}\text { Initial } \\
\text { tensile } \\
\text { modulus }\end{array}$ & $\begin{array}{c}\text { Breaking } \\
\text { strain }\end{array}$ & $\begin{array}{l}\text { Breaking } \\
\text { tenacity }\end{array}$ \\
\hline 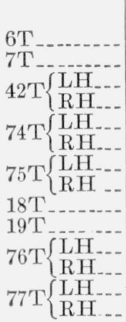 & $\begin{array}{l}m / s e c \\
45.3 \\
43.0 \\
44.9 \\
44.9 \\
42.2 \\
42.2 \\
42.5 \\
42.5 \\
65.7 \\
66.4 \\
62.5 \\
62.5 \\
64.2 \\
64.2\end{array}$ & $\begin{array}{l}c m \\
60 \\
60 \\
40 \\
40 \\
40 \\
40 \\
40 \\
40 \\
60 \\
60 \\
40 \\
40 \\
40 \\
40\end{array}$ & $\begin{array}{l}\text { \%/sec } \\
1,500 \text { to } 7,000 \\
1,000 \text { to } 5,000 \\
2,000 \text { to } 9,500 \\
2,000 \text { to } 8,500 \\
2,000 \text { to } 8,000 \\
2,000 \text { to } 6,500 \\
2,000 \text { to } 6,000 \\
2,000 \text { to } 8,500 \\
2,500 \text { to } 9,500 \\
2,500 \text { to } 9,000 \\
4,500 \text { to } 12,500 \\
4,000 \text { to } 12,500 \\
4,000 \text { to } 14,500 \\
4,000 \text { to } 14,000\end{array}$ & $\begin{array}{l}\quad s e c \\
3.73 \times 10^{-3} \\
3.92 \\
2.62 \\
2.62 \\
2.59 \\
2.59 \\
2.74 \\
2.68 \\
2.70 \\
2.67 \\
1.74 \\
1.74 \\
1.83 \\
1.83\end{array}$ & $\begin{array}{c}\text { g/denier } \\
50 \\
65 \\
50 \\
60 \\
50 \\
50 \\
50 \\
55 \\
65 \\
60 \\
60 \\
65 \\
60 \\
65\end{array}$ & $\begin{array}{l}\% \\
14.8 \\
14.4 \\
15.0 \\
14.7 \\
13.2 \\
13.1 \\
15.5 \\
14.5 \\
15.0 \\
15.3 \\
14.8 \\
14.8 \\
15.6 \\
15.7\end{array}$ & $\begin{array}{c}\text { g/denier } \\
7.50 \\
7.10 \\
7.60 \\
6.10 \\
8.60 \\
7.10 \\
8.70 \\
7.85 \\
7.10 \\
6.80 \\
8.20 \\
9.20 \\
7.40 \\
6.75\end{array}$ \\
\hline
\end{tabular}

a Nylon tested was duPont type 300, 5 ply, 210 denier per ply, $3 \mathrm{Z}$ twist, 1085 denier total, obtained from U. S. Army Quartermaster. Specimens were impacted transversely midway between clamps. In tests $42 \mathrm{~T}$ and $74 \mathrm{~T}$ to $77 \mathrm{~T}$, the lengths were sufficiently short that the entire specimen could be photographed and separate analyses made for the segments on each side of the impacting projectile.

of the scallops indicates how the tension depends upon the local strain.

The dotted line stress-strain curve in figure 6 is obtained by plotting data taken from figure 5. The scallops are due principally to use of the average strain, $\bar{\epsilon}$, in the plotting and the calculations, rather than the local strain at the transverse wave front. The average strain just before reflection of the transverse wave (indicated by $R$ ) most closely approximates this local strain. The smoothed stress-strain curve, shown as a solid line, is drawn through these points.

As an indication of the reproducibility of this method for obtaining stress-strain curves, data from a number of tests on nylon yarn specimens are presented in table 1. It is evident from these data that if duplicate tests are made with transverse impact velocity and specimen length kept constant, the values obtained for breaking tenacity, breaking strain, and initial modulus are in good agreement. Moreover these properties are not affected greatly by the range of impact velocities and specimen lengths used in these tests.

In table 1 , tests $6 \mathrm{~T}$ and $7 \mathrm{~T}$, in which the specimen half-length, $L$, is $30 \mathrm{~cm}$, have an average breaking time of $3.8 \times 10^{-3}$ sec and an average breaking strain of 14.6 percent. The corresponding average rate of straining is roughly 4,000 percent per second. Similarly for tests $42 \mathrm{~T}, 74 \mathrm{~T}$, and $75 \mathrm{~T}$, in which $L$ is $20 \mathrm{~cm}$, the average rate of straining is 5,500 percent per second. Of the tests conducted at 65 $\mathrm{m} / \mathrm{sec}, 18 \mathrm{~T}$ and $19^{\prime} \mathrm{T}$, for which $L$ is $30 \mathrm{~cm}$, have an average rate of straining of 5,500 percent per second, and $76 \mathrm{~T}$ and $77 \mathrm{~T}$, with $L 20 \mathrm{~cm}$, have an average rate of straining of 8,500 percent per second. Curves of average data for the four tests just described are plotted in figure 7 . These four curves do not differ greatly so the curve of average data for all the tests listed in table 1 may be considered representative. This curve is plotted in figure 8, and the rate of straining assigned is 5,000 percent per second.

The stress-strain curves for nylon at low rates of straining, plotted in figure 8, were obtained with an Instron tensile tester. These curves are average data from five tests each on specimens 10 in. long. The specimens were conditioned and tested at a temperature of $72^{\circ} \mathrm{F}$ and relative humidity of 50 percent. (The temperature and humidity in the room where the transverse impact tests were made were not controlled.)

Similar data for Fortisan and Fiberglas are presented in figures 9 and 10 and in tables 2 and 3 .

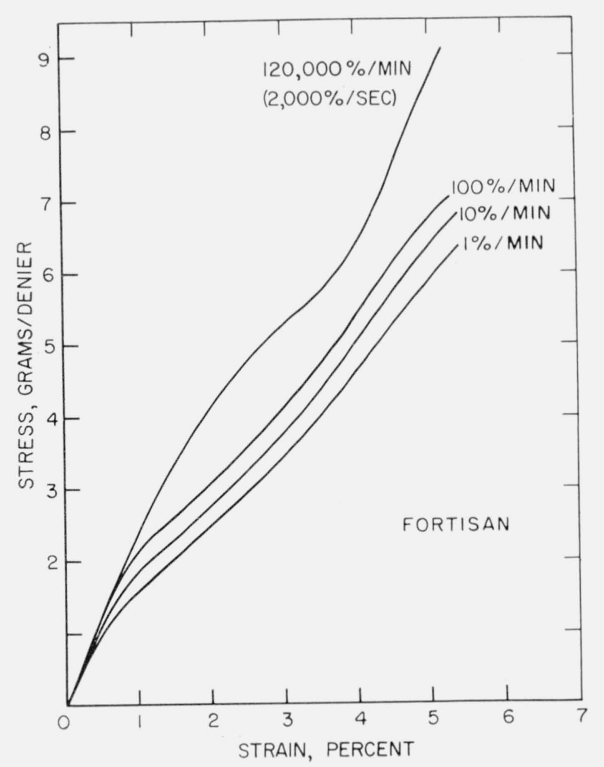

Figure 9. Stress-strain curves for Fortisan at various rates of straining. 


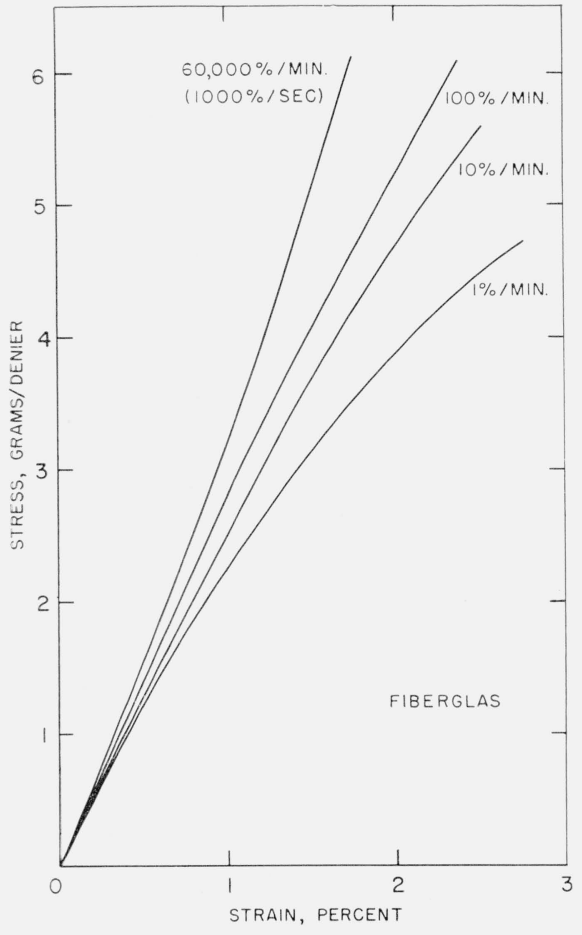

FIGURE 10. Stress-strain curves for Fiberglas 150-1/0 at various rates of straining.
TABle 4. Tenacities, elongations, and initial tensile moduli for nylon, Fortisan, and Fiberglas

\begin{tabular}{|c|c|c|c|c|}
\hline Material & Rate of straining & $\begin{array}{l}\text { Initial ten- } \\
\text { sile mod- } \\
\text { ulus }\end{array}$ & $\begin{array}{c}\text { Breaking } \\
\text { strain }\end{array}$ & $\begin{array}{l}\text { Breaking } \\
\text { tenacity }\end{array}$ \\
\hline $\begin{array}{l}\text { High-tenacity } \\
\text { nylon. }\end{array}$ & $\begin{array}{r}\% / m i n \\
1 \\
10 \\
100 \\
300,000 \\
(5,000 \% / \mathrm{sec})\end{array}$ & $\begin{array}{c}\text { g/denier } \\
36 \\
41 \\
45 \\
57\end{array}$ & $\begin{array}{l}\% \\
16.7 \\
17.6 \\
16.1 \\
14.7\end{array}$ & $\begin{array}{c}\text { g/denier } \\
6.28 \\
6.76 \\
6.97 \\
7.57\end{array}$ \\
\hline Fortisan .... & $\begin{array}{r}1 \\
10 \\
100 \\
120,000 \\
(2,000 \% / \mathrm{sec})\end{array}$ & $\begin{array}{l}168 \\
199 \\
251 \\
256\end{array}$ & $\begin{array}{l}5.4 \\
5.4 \\
5.3 \\
5.2\end{array}$ & $\begin{array}{l}6.33 \\
6.80 \\
7.04 \\
9.10\end{array}$ \\
\hline Fiberglas _.. & $\begin{array}{r}1 \\
10 \\
100 \\
60,000 \\
(1,000 \% / \mathrm{sec})\end{array}$ & $\begin{array}{l}249 \\
260 \\
279 \\
324\end{array}$ & $\begin{array}{l}2.8 \\
2.5 \\
2.4 \\
1.8\end{array}$ & $\begin{array}{l}4.73 \\
5.58 \\
6.07 \\
6.12\end{array}$ \\
\hline
\end{tabular}

Table 4 summarizes the average data characterizing: the curves plotted in figures 8, 9, and 10. In comparing the data for nylon, Fortisan, and Fiberglas it is seen that in each case increasing the rate of straining tends to make the slope of the stress-strain curve steeper at the origin; i. e., increases the initial tensile modulus. In addition the initial linearity of the stress-strain curve persists up to increasingly large values of the stress. This type of behavior has previously been observed by Meredith for textile

Table 2. Transverse impact data for Fortisan a

\begin{tabular}{|c|c|c|c|c|c|c|c|}
\hline Test & $\begin{array}{l}\text { Impact } \\
\text { velocity }\end{array}$ & $\begin{array}{l}\text { Specimen } \\
\text { length }\end{array}$ & Rate of straining & $\begin{array}{l}\text { Time to } \\
\text { break }\end{array}$ & $\begin{array}{l}\text { Initial } \\
\text { tensile } \\
\text { modulus }\end{array}$ & $\begin{array}{l}\text { Breaking } \\
\text { strain }\end{array}$ & $\begin{array}{l}\text { Breaking } \\
\text { tenacity }\end{array}$ \\
\hline $\begin{array}{l}8 \mathrm{~T} \\
81 \mathrm{~T} \\
82 \mathrm{~T} \\
83 \mathrm{~T} \\
84 \mathrm{~T}\end{array}$ & $\begin{array}{l}\mathrm{m} / \mathrm{sec} \\
46.2 \\
40.6 \\
41.3 \\
41.2 \\
41.3\end{array}$ & $\begin{array}{l}c m \\
60 \\
60 \\
60 \\
60 \\
60\end{array}$ & $\begin{array}{c}\% / \mathrm{sec} \\
1,000 \text { to } 4,000 \\
1,000 \text { to } 3,500 \\
1,000 \text { to } 3,500 \\
1,000 \text { to } 3,500 \\
1,000 \text { to } 3,000\end{array}$ & $\begin{array}{l}\quad s e c \\
\text { 1. } 70 \times 10^{-3} \\
2.53 \\
2.50 \\
2.47 \\
2.35\end{array}$ & $\begin{array}{c}\text { g/denier } \\
260 \\
250 \\
260 \\
250 \\
260\end{array}$ & $\begin{array}{l}\% \\
4.5 \\
5.9 \\
5.7 \\
5.3 \\
4.7\end{array}$ & $\begin{array}{c}g / \text { denier } \\
8.70 \\
9.20 \\
9.70 \\
10.10 \\
7.80\end{array}$ \\
\hline
\end{tabular}

a Fortisan tested was a high-tenacity deacetylated cellulose acetate yarn, 3 ply, 270 denier per ply, $2.5 \mathrm{Z}$ twist, 787 denier total, obtained from the Celanese Corporation of America.

TABLE 3. Transverse impact data for Fiberglas a

\begin{tabular}{|c|c|c|c|c|c|c|c|}
\hline Test & $\begin{array}{l}\text { Impact } \\
\text { velocity }\end{array}$ & $\begin{array}{l}\text { Specimen } \\
\text { length }\end{array}$ & Rate of straining & $\begin{array}{l}\text { Time to } \\
\text { break }\end{array}$ & $\begin{array}{l}\text { Initial } \\
\text { tensile } \\
\text { modulus }\end{array}$ & $\begin{array}{c}\text { Breaking } \\
\text { strain }\end{array}$ & $\begin{array}{l}\text { Breaking } \\
\text { tenacity }\end{array}$ \\
\hline $\begin{array}{l}24 \mathrm{~T} \\
91 \mathrm{~T} \\
92 \mathrm{~T} \\
93 \mathrm{~T} \\
94 \mathrm{~T}\end{array}$ & $\begin{array}{l}m / s e c \\
41.9 \\
41.0 \\
43.1 \\
39.9 \\
40.0\end{array}$ & $\begin{array}{l}c m \\
60 \\
60 \\
60 \\
60 \\
60\end{array}$ & $\begin{array}{c}\% / \mathrm{sec} \\
900 \text { to } 1,700 \\
800 \text { to } 2,000 \\
900 \text { to } 2,100 \\
1,000 \text { to } 2,000 \\
700 \text { to } 2,000\end{array}$ & $\begin{array}{l}\quad s e c \\
1.41 \times 10^{-3} \\
\text { 1. } 40 \\
1.48 \\
1.50 \\
1.51\end{array}$ & $\begin{array}{c}\text { g/denier } \\
320 \\
320 \\
320 \\
330 \\
330\end{array}$ & $\begin{array}{l}\% \\
1.76 \\
1.70 \\
1.75 \\
1.70 \\
1.81\end{array}$ & $\begin{array}{c}\text { g/denier } \\
5.65 \\
6.65 \\
6.75 \\
5.15 \\
6.40\end{array}$ \\
\hline
\end{tabular}

a Sample tested was Fiberglas 150-1/0, 1 Z (323 denier) obtained from the Owens-Corning Fiberglas Corp. 
varns [5], by the authors for hair and silk [6], and by Campbeil for mild steel [7]. It is similar to the type of behavior observed when the stress-strain curve is obtained at standard rates of straining, but at low temperatures. Typical curves for specimens measured under these conditions have been published by Kaswell [8] and by Coplon [9].

The stress-strain curves for Fiberglas, figure 10, become increasingly linear in the rate of straining range 1 to 100 percent per minute. However, the nonlinearity of the 1 percent per minute curve may be attributed in part to filament slippage. The 1,000 percent per second curve is slightly concave upward. This latter effect may be attributed to the increase in rate of straining which occurs in this method at increasing stress.

The support of this work by the Quartermaster Research and Development Command, U. S. Army, and permission to publish are gratefully acknowledged.

Washington, April 6, 1956.

\section{References}

[1] W. K. Stone, H. F. Schiefer, and G. Fox, Stress-strain relationships in yarns subjected to rapid impact loading: 1. Equipment, testing procedure, and typical results, J. Research NBS 54, 269 (1955) RP2589; Textile Research J. 25, 520 (1955).

[2] F. L. MeCrackin, H. F. Schiefer, J. C. Smith, and W. K. Stone, Stress-strain relationships in yarns subjected to rapid impact loading: 2. Breaking velocities, strain energies, and theory neglecting wave propagation, J. Research NBS 54, 277 (1955) RP2690; Textile Research J. 25, 529 (1955).

[3] J. C. Smith, F. L. McCrackin, and H. F. Schiefer, Stressstrain relationships in yarns subjected to rapid impact loading: 3. Effect of wave propagation, J. Research NBS 55, 19 (1955) RP2601; Textile Research J. 25, 701 (1955).

[4] J. W. Craggs, Wave motion in plastic-elastic strings, J. Mech. and Physies of Solids ?, 286 (1954).

[5] R. Meredith, the effect of rate of extension on the textile behavior of viscose and acetate rayons, silk, and nylon, J. Textile Inst. 45, T30-T43 (1954).

[6] H. F. Schiefer, J. C. Smith, F. L. MeCrackin, W. K. Stone, and K. M. Towne, Stress-strain relationships in yarns tested at rates of straining up to a million percent per minute, Proc. Intl. Wool Textile Research Conference, Australia (1955.)

[7] W. R. Campbell, Dynamic stress-strain curves for mild steel using the tangent modulus procedure, J. Wash. Acad. Sci. 43, 102 (1953).

[8] E. R. Kaswell, Low temperature properties of textile materials, Am. Dyestuff Rept. 38, 127-34 (1949).

[9] M. J. Coplon, A study of the effect of temperature on textile materials, Wright Air Development Center Technical Report 53-21 (March 1953). Available as PB111240 from Office of Technical Services, U. S. Department of Commerce, or E. R. Kaswell, Textile fibers yarns and fabrics, Reinhold Publishing Corp., N. Y., (1953) pp. 18-20. 